\title{
Tunicamycin specifically aggravates ER stress and overcomes chemoresistance in multidrug-resistant gastric cancer cells by inhibiting N-glycosylation
}

\author{
Jian $\mathrm{Wu}^{\dagger}$, Sheng Chen ${ }^{\dagger}$, Hao Liư ${ }^{\dagger}$ Zhe Zhang, Zhen Ni, Jie Chen, Zhiping Yang, Yongzhan Nie and Daiming Fan ${ }^{*}$
}

\begin{abstract}
Background: Multidrug resistance remains a major obstacle to successful treatment for patients with gastric cancer (GC). Recently, glycosylation has been demonstrated to play a vital role in the acquisition of multidrug resistance. As a potent inhibitor of glycosylation, tunicamycin (Tu) has shown marked antitumor activities in various cancers. In the present study, we attempted to determine the exact effect of Tu on the chemoresistance of GC.

Methods: The cytotoxic effects of drugs on GC cells were evaluated by cell viability assays, and apoptosis was detected by flow cytometry. PCR, western blot analysis, immunofluorescence staining and canonical inhibitors were employed to identify the underlying mechanisms of the specific effects of Tu on multidrug-resistant (MDR) GC cells.

Results: For the first time, we found that MDR GC cells were more sensitive to Tu-induced cell death than the parental cells and that the increased sensitivity might correlate with basal endoplasmic reticulum (ER) stress. In addition, Tu dramatically increased chemotherapy-induced apoptosis by evoking ER stress in GC cells, particularly MDR cells. Further study indicated that these effects were highly dependent on glycosylation inhibition by Tu, rather than its role as a canonical ER stress inducer. Besides, autophagy was markedly triggered by Tu, and blocking autophagy enhanced the combined effects of Tu and chemotherapy on MDR GC cells.
\end{abstract}

Conclusions: Our results suggest that tumor-targeted glycosylation inhibition may be a feasible strategy to reverse chemoresistance in GC patients.

Keywords: Gastric cancer, Multidrug resistance, Tunicamycin, Glycosylation, ER stress, Autophagy

\section{Background}

Gastric cancer (GC) is the second leading cause of cancer-related mortality in China and one of the most common causes of cancer-related deaths worldwide [1, 2]. Despite the substantial improvements made in the screening and treatment of GC in recent decades, it remains a devastating disease with dismal survival rates [3]. The development of multidrug resistance is a major reason for the poor prognosis of GC patients. Thus, it is imperative to identify the Achilles' heel of multidrug

\footnotetext{
* Correspondence: yongznie@fmmu.edu.cn; fandaim@fmmu.edu.cn ${ }^{\dagger}$ Jian Wu, Sheng Chen and Hao Liu contributed equally to this work. State Key Laboratory of Cancer Biology, National Clinical Research Center for Digestive Diseases and Xijing Hospital of Digestive Diseases, Fourth Military Medical University, 127 West Changle Road, Xi'an 710032, Shaanxi, China
}

resistance that could be exploited for the development of more effective therapeutics to treat GC patients.

As a major post-translational modification (PTM), glycosylation plays a vital role in the folding, stability, subcellular localization and biological functions of glycoproteins. At present, aberrant glycosylation has been widely recognized as an important hallmark of cancer and significantly correlates with the development, progression, metastasis and chemoresistance of tumors [4-12]. Our previous studies demonstrated that the dysregulated glycosylation of P-gp greatly impacted its function in the multidrug resistance of GC [13], and the aberrant glycosylation of secreted proteins might be involved in the development of multidrug resistance in GC cells [14]. Initially identified as a natural antibiotic, tunicamycin $(\mathrm{Tu})$ is also a canonical

(C) The Author(s). 2018 Open Access This article is distributed under the terms of the Creative Commons Attribution 4.0 International License (http://creativecommons.org/licenses/by/4.0/), which permits unrestricted use, distribution, and 
compound for blocking $\mathrm{N}$-linked glycosylation by inhibiting the transfer of UDP-N-acetylglucosamine (GlcNAc) to dolichol phosphate in the endoplasmic reticulum (ER) of eukaryotic cells, thus disrupting protein maturation [1517]. Based on these, Tu has been identified as a promising anticancer therapeutic. It was reported that Tu could promote apoptosis and sensitize cancer cells to chemotherapy and radiation therapy [18-21]. Other studies showed that $\mathrm{Tu}$ treatment could reverse chemoresistance in several cancers, at least partially [22-24]. Wojtowicz et al. showed that $\mathrm{Tu}$ significantly increased the chemotherapy-induced death of drug-resistant cancer cells by regulating the function and localization of P-gp and BCRP [22].

Moreover, by inhibiting protein glycosylation, Tu could potently trigger ER stress. The ER is a dynamic network of tubules involved in the synthesis, folding and processing of over a third of the total cellular proteome. In tumor cells, the protein-processing machinery in the ER is often challenged by either intrinsic stresses, such as oncogenic activation and point mutation, or extrinsic perturbations, such as hypoxia, nutrient deprivation and acidosis. All of these would alter protein homeostasis and lead to the accumulation of misfolded proteins in the ER lumen, a state known as ER stress. Upon the initiation of ER stress, cells evoke a series of adaptive mechanisms to enhance the folding and clearance capacities, thus restoring ER proteostasis; this process is called the unfolded protein response (UPR). The UPR is mediated by three stress sensors located in the ER, namely activating transcription factor 6 (ATF6), PKR-like ER kinase (PERK) and inositol-requiring enzyme1 (IRE1). Although the UPR is initially activated as a cytoprotective response, prolonged ER stress can result in apoptosis [25-27]. Studies have shown that Tu-induced ER stress can commit cells to apoptosis [23, 24, 28]. However, there have been limited studies regarding the effects of Tu on GC.

Here, we report that $\mathrm{Tu}$ preferentially triggers cell death in multidrug-resistant (MDR) GC cells and significantly enhances apoptosis induced by chemotherapy through exacerbating ER stress. Moreover, we find that these specific effects are highly dependent on the inhibition of glycosylation by $\mathrm{Tu}$. In addition, blocking ER stress-induced autophagy markedly increases the apoptosis of MDR GC cells under combined treatment with $\mathrm{Tu}$ and chemotherapy. Therefore, we believe that developing novel drugs that specifically inhibit glycosylation in tumor cells will improve the efficacy of chemotherapy for GC patients in the clinic, which deserves further research.

\section{Methods}

\section{Reagents and antibodies}

Adriamycin (Adr), vincristine sulfate (Vcr), hydroxychloroquine Sulfate (HCQ) and brefeldin A (BFA) were purchased from Selleck Chemicals (Houston, TX, USA). Tunicamycin ( $\mathrm{Tu}$, ab120296) was purchased from Abcam (Cambridge, MA, USA). Thapsigargin (Tg, \#12758) was from Cell Signaling Technology (Danvers, MA, USA). Tu, Tg and BFA were dissolved in DMSO and then diluted with RPMI-1640 medium for subsequent experiments. Additionally, Adr, Vcr and HCQ were dissolved in PBS and diluted with RPMI-1640 medium for further experiments. Anti-rabbit IgG (\#7074), anti-mouse IgG (\#7076) and antibodies against cleaved caspase-3 (\#9664), cleaved caspase-7 (\#8438), cleaved PARP (\#5625), $\beta$-actin (\#8457), PERK (\#5683), IRE1 $\alpha$ (\#3294), Bip (\#3177), XBP1s (\#12782), PDI (\#3501), CHOP (\#2895), L1CAM (\#89861), and TIMP1 (\#8946) were from Cell Signaling Technology. Goat anti-mouse IgG Alexa Fluor 488 (ab150113), donkey anti-rabbit IgG Alexa Fluor 594 (ab150076) and antibodies against p-IRE1 (ab124945), LC3B (ab192890) and P62 (ab56416) were from Abcam.

\section{Cell culture}

The human gastric adenocarcinoma cell line SGC7901 was obtained from the Academy of Military Medical Science (Beijing, China). The MDR derivatives SGC7901/ ADR (ADR) and SGC7901/VCR (VCR) were developed and maintained as previously described [14]. Other gastric cancer cell lines (BGC823, MKN45, AGS) and the human immortalized gastric epithelial cell line (GES) were from the cell bank of our lab. All cell lines were cultured in RPMI-1640 medium with 10\% FBS, $100 \mathrm{U} / \mathrm{ml}$ penicillin sodium and $100 \mathrm{mg} / \mathrm{ml}$ streptomycin sulfate at $37^{\circ} \mathrm{C}$ in a humidified atmosphere containing $5 \% \mathrm{CO}_{2}$.

\section{Cell viability assay}

Cell viability was measured with Cell Counting Kit-8 (DOJINDO, Kumamoto, Japan) according to the manufacturer's instructions. Cells were seeded in 96-well plates at a density of $3 \times 10^{3}$ cells/well with five replicates and incubated overnight. We then treated the cells with the appropriate drugs. After treatment, the original medium was replaced with a mixture of $10 \mu \mathrm{l}$ CCK- 8 reagent and $100 \mu \mathrm{l}$ fresh medium. Cells were incubated for another $4 \mathrm{~h}$ at $37^{\circ} \mathrm{C}$. Finally, the absorbance of each well was measured by a microplate reader (Varioskan Flash, Thermo Scientific) at $450 \mathrm{~nm}$. Every experiment was performed in triplicate.

\section{Apoptosis assay by flow cytometry}

GC cells were grown in 6-well plates and treated with the appropriate chemicals for the desired period. After treatment, the cells were harvested and then resuspended in binding buffer. Afterwards, the cells were incubated with Annexin V-FITC and PI (Beyotime, China) according to the manufacturer's instructions. Subsequently, the cells 
were analyzed with a flow cytometer (FACScan, BD Biosciences, USA). All experiments were performed in triplicate.

\section{Western blot analysis}

Protein expression was determined by western blot analysis. The cells were grown in 6-well plates and then lysed with RIPA buffer (Beyotime, Shanghai, China) containing a complete ${ }^{\bullet}$ protease inhibitor cocktail (Roche, Manheim, Germany). The protein concentration was determined using a BCA kit (Thermo Scientific, USA). Protein samples $(30 \mu \mathrm{g})$ were separated on SDS-PAGE gels and then transferred to PVDF membranes (Thermo Scientific, USA). Afterwards, the membranes were blocked in 5\% nonfat milk and incubated with antibodies as described in our previous work [14]. Protein signals were detected by the ChemiDoc XRS+ imaging system (BIO-RAD, CA, USA) using the ECL reagent (Millipore, MA, USA) and quantified by Image Lab software (BIO-RAD). All experiments were performed in triplicate.

\section{Immunofluorescence analysis}

The cell immunofluorescence assay was performed with a CST immunofluorescence application solutions kit (\#12727) according to the standard protocol. After incubation with antibodies, the cells were counterstained with ProLong ${ }^{\circ}$ Gold Antifade Reagent with DAPI (\#8961). Then, the cells were visualized and photographed using an Olympus confocal laser scanning microscope FV1200.

\section{PCR array and data analysis}

Changes in UPR-related genes were determined by the $\mathrm{RT}^{2}$ Profiler $^{\mathrm{rm}}$ PCR Array-Human Unfolded Protein Response (PAHS-089Z, Qiagen). Cells were grown in 6-well plates and subjected to treatments for $48 \mathrm{~h}$ before being harvested for further analysis. Total RNA was isolated using the Qiagen RNeasy Mini Kit, and cDNA was synthesized using the Qiagen $\mathrm{RT}^{2}$ First Strand Kit. The subsequent procedures followed the instructions provided by Qiagen. The reactions were performed with Bio-Rad CFX96. The web-based analysis tool of Qiagen was used to interpret the results. In addition, GO analysis of the identified genes was conducted with the PANTHER classification system.

\section{Statistical analysis}

The data are expressed as the mean $\pm \mathrm{SD}$. Statistical analysis was performed using one-way ANOVA in GraphPad Prism (version 7.0). Differences were considered statistically significant when $\mathrm{P}$ was $<0.05$.

\section{Results \\ Basal ER stress determines the higher sensitivity of MDR cells to $\mathrm{Tu}$}

To explore the effects of Tu on GC cells, we identified the dose-response curves of GES and 6 gastric cancer cell lines, including two derivative MDR cell lines. In general, the cytotoxicity assay indicated that GES was more sensitive to $\mathrm{Tu}$ than any other cell line, demonstrating the more toxic effects of Tu on normal tissues. Moreover, as for the MDR cell models, MDR cells (SGC7901/ADR and SGC7901/VCR) showed higher sensitivity to Tu than the parental cells (SGC7901) (Fig. 1a).
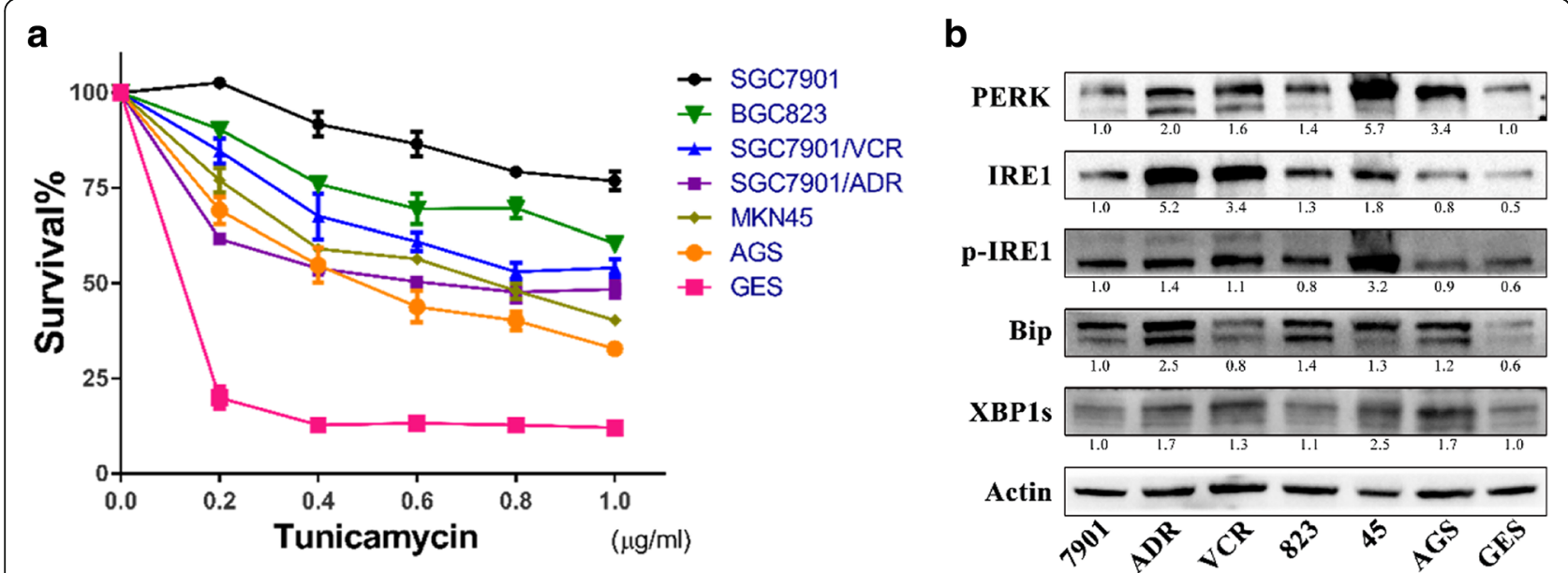

Fig. 1 Tunicamycin exerts strong cytotoxic effects on MDR GC cells, which correlates with basal ER stress. a Cell survival after Tu treatment for $48 \mathrm{~h}$ assayed by CCK-8. Tu, tunicamycin. The values in the untreated group are identified as the baseline, namely $100 \%$ survival. $\mathbf{b}$ Expressions of ER stress-associated proteins in cells without treatment. $\beta$-actin served as the loading control. All proteins were normalized to $\beta$-actin. ER, endoplasmic reticulum; 7901, SGC7901; ADR, SGC7901/ADR; VCR, SGC7901/NCR; 823, BGC823; 45, MKN45; GES, human immortalized gastric epithelial cell line 
Given that Tu can activate ER stress and that excess ER stress leads cells to death, we determined the expressions of ER stress-associated proteins in cells without treatment by western blot (WB) analysis. The results showed that PERK, p-IRE1, IRE1 and XBP1s were all upregulated in MDR cells compared to those in the parental cells, except for Bip. Bip was slightly downregulated in SGC7901/VCR compared to SGC7901. When the expressions of all the proteins were considered comprehensively, we believed that compared to the parental cells, MDR GC cells displayed higher levels of basal ER stress (Fig. 1b), which could be the determinant factor driving their greater susceptibility to $\mathrm{Tu}$. That deserves further exploration.

Tu preferentially induces MDR cells to death in a time/ dose-dependent manner by aggravating ER stress We treated the two MDR cell lines (SGC7901/ADR and SGC7901/VCR) and their parental cell line SGC7901 with $\mathrm{Tu}(0-1 \mu \mathrm{g} / \mathrm{ml})$ for 24,48 and $72 \mathrm{~h}$ to obtain more detailed information about their responses to Tu. Generally, we found that $\mathrm{Tu}$ preferentially reduced the viability of MDR cells in a time/dose-dependent manner (Fig. 2a). Furthermore, after exposure to Tu for $48 \mathrm{~h}$, MDR cells exhibited more significant enhancements of ER stress-associated proteins (PERK, IRE1, Bip, CHOP) with increasing doses, as demonstrated by WB analysis (Fig. 2b) and immunocytochemical staining (Fig. 2c). Based on the above results, we believed that Tu could specifically exacerbate basal ER stress in MDR cells, which made them more vulnerable to Tu treatment.

\section{Tu potently increases drug-induced apoptosis in MDR} cells via further enhancing ER stress

Because MDR GC cells were more susceptible to Tu, we next explored whether Tu could overcome chemoresistance in GC cells. Cell viability assays indicated that cotreatment of $\mathrm{Tu}(0.2 / 0.4 / 0.8 \mu \mathrm{g} / \mathrm{ml})$ with Adr could significantly reduce cell survival in MDR cells at any dose of $\mathrm{Tu}$, whereas only the large concentration of $\mathrm{Tu}$ $(0.8 \mu \mathrm{g} / \mathrm{ml})$ could markedly enhance cell death in the parental cell line (Fig. 3a). To further identify the interaction between $\mathrm{Tu}$ and Adr, we calculated the Combination index (CI) values (Additional file 1: Table S1) for GC cells using CompuSyn software. Disappointingly, despite the fact that combined therapy with Tu and Adr could induce more cell death than monotherapy with Adr, the combination did not indicate synergistic effects for MDR cells. Despite this, dual therapy with Tu and Adr triggered significantly more apoptosis of GC cells than monotherapy with Adr (Fig. 3b). Taken together, these results showed that Tu could decrease the chemoresistance of MDR cells to some extent.
To elucidate the underlying mechanism, we performed the PCR array for SGC7901 and SGC7901/ADR after treatment with Adr alone or Adr and Tu. The results showed that in SGC7901/ADR, the differentially expressed genes between the CT (combined therapy with Tu and Adr) group and the Adr group were mainly involved in the UPR and apoptosis signaling pathways (Fig. 3c), which was further evidenced by GO analysis of these identified genes (Additional file 2: Figure S1). However, we found few changes in such genes in SGC7901 between the CT group and Adr group (Additional file 3: Figure S2).

Moreover, at the protein level, we carried out WB and immunofluorescence (IF) experiments to explore the changes in UPR- and apoptosis-related proteins in SGC7901 and SGC7901/ADR after monotherapy (Adr) or CT (Adr and $\mathrm{Tu}$ ). Our results indicated that Bip (GRP78), an important modulator of ER stress, was significantly increased in the CT group of SGC7901/ADR compared to the Adr group. We also identified the notable up-regulation of CHOP (C/EBP homologous protein), a key player in UPR-mediated apoptotic pathway, in the CT group of SGC7901/ADR. In addition, the effects of CT in SGC7901/ADR were further evidenced by increases in cleaved caspases and PARP (Fig. 3d). Furthermore, in SGC7901/ADR, IF assays of CHOP, Cl-caspase 3 and Cl-PARP also demonstrated marked enhancements in the CT group compared to the Adr group (Fig. 3e). However, the increases in these proteins were not as significant in the CT group of SGC7901 (Fig. 3d and Additional file 4: Figure S3). Generally, our results demonstrated that CT could induce more apoptosis by aggravating ER stress in MDR GC cells, thus reversing chemoresistance.

\section{The specific impacts of Tu on MDR cells strongly depend on its inhibition of $\mathrm{N}$-glycosylation}

As already reported, Tu potently induces ER stress by inhibiting the $\mathrm{N}$-linked glycosylation of glycoproteins. However, thapsigargin ( $\mathrm{Tg}$ ) functions as another ER stress inducer by disrupting $\mathrm{Ca}^{2+}$ homeostasis in the ER. Hence, to determine whether the specific effects of $\mathrm{Tu}$ on MDR GC cells were mainly due to its inhibition of $\mathrm{N}$-glycosylation or its role as an ER stress inducer, we attempted to mimic its particular influences on MDR cells using $\mathrm{Tg}$.

First, we compared the responses of SGC7901, SGC7901/ADR and SGC7901/VCR to Tg and Tu, respectively, across large dosage ranges $(0.125-16 \mu \mathrm{g} / \mathrm{ml}$ for Tg; $0.25-16 \mu \mathrm{g} / \mathrm{ml}$ for $\mathrm{Tu}$ ). The results of CCK-8 assays showed that the two MDR cell lines SGC7901/ADR and SGC7901/VCR were less sensitive to Tg compared to the parental cell line, which was opposite to the effects of Tu on these 3 cell lines (Fig. 4a). 


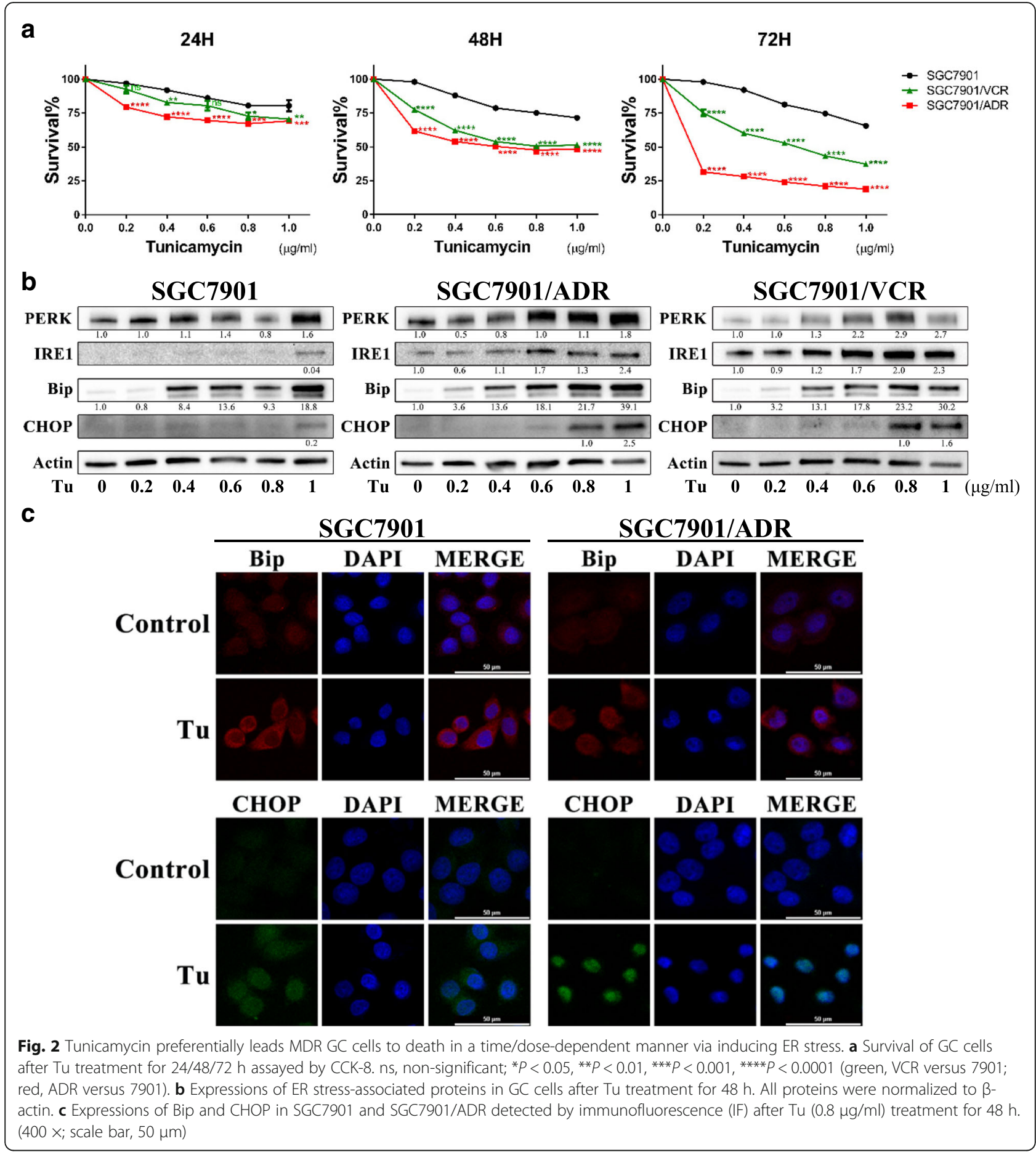

In addition, to verify its function of inducing ER stress, we incubated the 3 cell lines with $\mathrm{Tg}(2 \mu \mathrm{g} / \mathrm{ml})$ for $48 \mathrm{~h}$ and subsequently determined the expressions of UPR-related proteins by WB. The results demonstrated that Tg could markedly activate ER stress, especially in SGC7901 (Fig. 4b).

Furthermore, we treated the 3 cell lines with dual therapy of $\mathrm{Adr}$ and $\mathrm{Tg}(0.5 / 2 \mu \mathrm{g} / \mathrm{ml})$ to explore whether $\mathrm{Tg}$ could potentiate the chemosensitivity of MDR cells to Adr. However, the cell viability assays indicated that $\mathrm{Tg}$ notably increased chemotherapy-induced cell death of SGC7901 at any dose but had little influence on the survival of MDR cells undergoing Adr treatment (Fig. 4c).

In addition, we employed another glycosylation inhibitor to further demonstrate the significance of glycosylation inhibition in the specific effects of $\mathrm{Tu}$ on MDR 


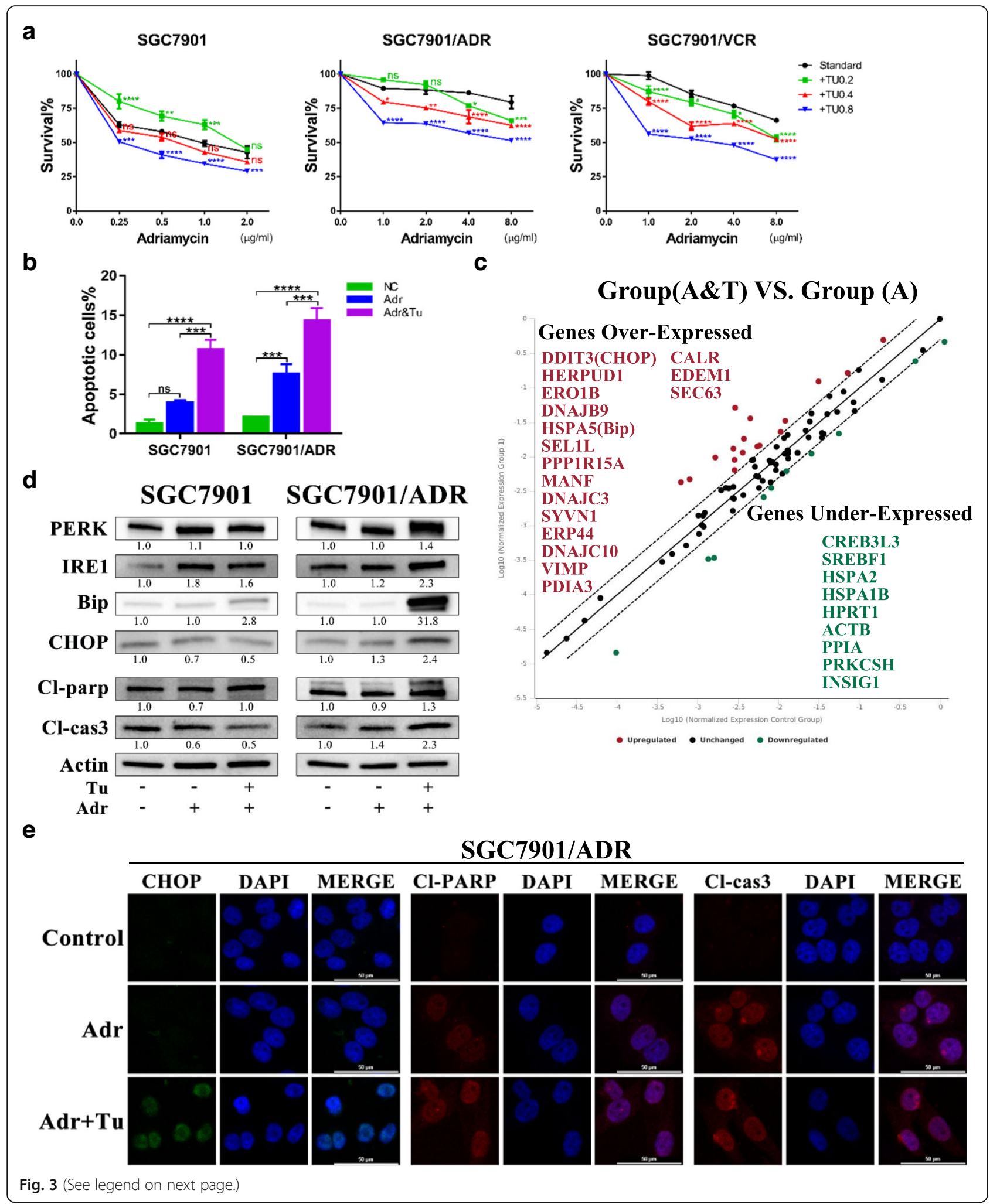


(See figure on previous page.)

Fig. 3 Tunicamycin increases chemotherapy-induced cell death by aggravating ER stress and enhancing apoptosis. a Survival of GC cells measured by CCK-8 after treatment with monotherapy (Adr) or dual therapy (Adr and Tu) for $48 \mathrm{~h}$. Adr, adriamycin; the concentrations of Tu were $0 / 0.2 / 0.4 / 0.8 \mu \mathrm{g} / \mathrm{ml}$. ns, non-significant; ${ }^{*} P<0.05$, ${ }^{* *} P<0.01$, ${ }^{* * *} P<0.001,{ }^{* * *} P<0.0001$ (green, + Tu 0.2 versus standard; red, + Tu 0.4 versus standard; blue, +Tu 0.8 versus standard). $\mathbf{b}$ Apoptotic cells detected by flow cytometry. Cells were subjected to monotherapy (Adr, 0.25/8 $\mu \mathrm{g} / \mathrm{ml}$ for SGC7901 and SGC7901/ADR, respectively) or dual therapy (Adr, same as the former; Tu, $0.8 \mu \mathrm{g} / \mathrm{ml}$ for both) for $48 \mathrm{~h}$ before the apoptosis assay. ns, non-significant; ${ }^{* * *} P<0.001,{ }^{* * *} P<0.0001$. The corresponding FCM graphs were shown in Additional file 7: Figure S6. c Changes in UPR-related genes assayed by PCR array in SGC7901/ADR (dual therapy group versus monotherapy group). Group (A \& T), dual therapy with Adr $(8 \mu \mathrm{g} / \mathrm{ml})$ and Tu $(0.8 \mu \mathrm{g} / \mathrm{ml})$ for $48 \mathrm{~h}$; Group (A), monotherapy with Adr $(8 \mu \mathrm{g} / \mathrm{ml})$ for $48 \mathrm{~h}$, the control group. The colored dots represent over-expressed or under-expressed genes; the black dots represent unchanged genes. $P<0.05$. $\mathbf{d}$ Expressions of proteins involved in the UPR and apoptosis signaling determined by WB in SGC7901 and SGC7901/ADR. Cells were subjected to the same treatments as above (3b) before protein extraction. All proteins were normalized to $\beta$-actin. e Expression levels of CHOP, Cl-PARP and Cl-caspase 3 in SGC7901/ADR detected by IF after treatment with monotherapy or dual therapy for $48 \mathrm{~h}$. The concentrations of drugs were the same as those in $3 c$. (400 x; scale bar, $50 \mu \mathrm{m})$

cells. First, we further illustrated the inhibitory effects of $\mathrm{Tu}$ on N-glycosylation by investigating example glycoproteins (Additional file 5: Figure S4a). L1CAM and TIMP1 are two identified glycoproteins modified with $\mathrm{N}$-glycans, as recorded in the Uniprot database. Our previous study discovered that the $\mathrm{N}$-glycosylation status of L1CAM and TIMP1 dramatically changed after the acquisition of chemoresistance in GC cells [14]. Thus, we explored whether Tu could inhibit the glycosylation of these two glycoproteins in GC cells. The WB results indicated that the expressions of L1CAM and TIMP1 decreased after Tu treatment $(0.8 \mu \mathrm{g} / \mathrm{ml})$ for $48 \mathrm{~h}$ in GC cells, particularly MDR cells (Additional file 5: Figure S4a). In addition, as indicated by Uniprot and our work [14], L1CAM possesses more glycosites and is modified with more $\mathrm{N}$-glycans. As a result, the expression of L1CAM is more vulnerable to glycosylation inhibition. Accordingly, the WB bands of L1CAM showed an obvious downward shift in MDR GC cells after $\mathrm{Tu}$ treatment (Additional file 5: Figure S4a). These results demonstrated that Tu could potently inhibit the N-glycosylation of glycoproteins in GC cells. Brefeldin A (BFA) can block protein transport from the ER to the Golgi apparatus and thus inhibit the glycosylation process. Therefore, we explored the effects of BFA on GC cells. The results demonstrated that MDR cells were more vulnerable to BFA treatment (Additional file 5: Figure S4b), and BFA could inhibit the glycosylation of L1CAM and activate ER stress in GC cells (Additional file 5: Figure S4c). More importantly, BFA significantly increased the chemosensitivity of GC cells to Adr (Additional file 5: Figure S4d). In
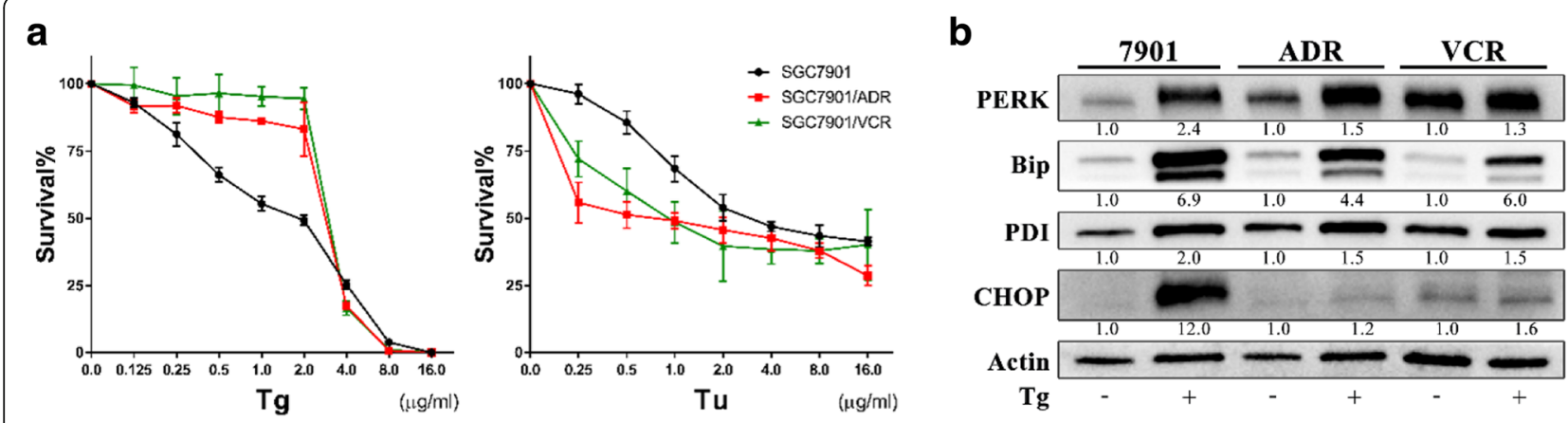

C SGC7901 SGC7901/ADR

SGC7901/VCR
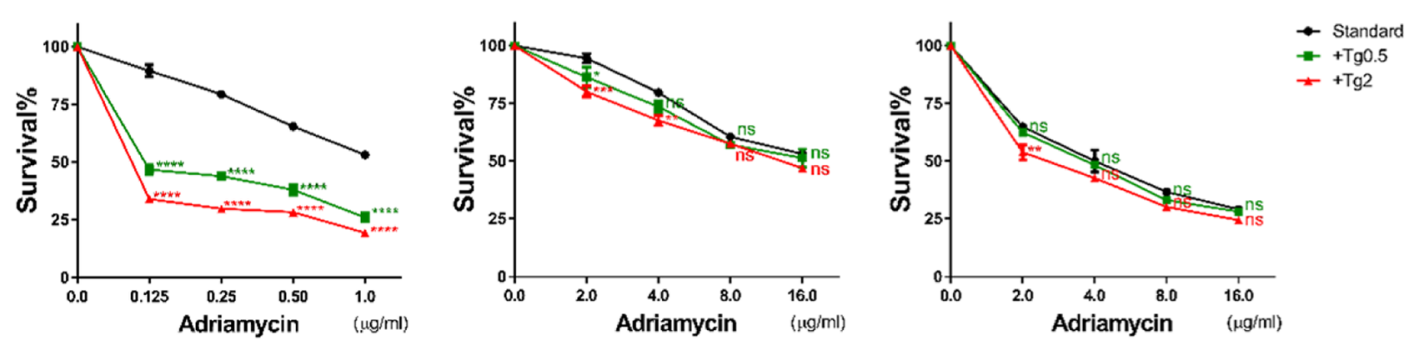

Fig. 4 Thapsigargin could not mimic the effects of tunicamycin on MDR GC cells. a Concentration-survival curves of GC cells treated with Tg or Tu (wide dose range) for $48 \mathrm{~h}$. Tg, thapsigargin. b Expressions of UPR-related proteins in GC cells after Tg treatment ( $2 \mu \mathrm{g} / \mathrm{ml})$ for $48 \mathrm{~h}$ determined by WB. All proteins were normalized to $\beta$-actin. c The effects of Tg on the chemosensitivity of GC cells after treatment for $48 \mathrm{~h}$. ns, non-significant; ${ }^{*} P<0.05,{ }^{* *} P<0.01,{ }^{* *} P<0.001,{ }^{* * *} P<0.0001$ (green $/ \mathrm{red},+\mathrm{Tg} 0.5 / 2$ versus standard, respectively) 
summary, our results indicated that BFA could mimic the effects of Tu on MDR cells to some extent.

In conclusion, our results demonstrated that compared to Tg, BFA could imitate the effects of Tu on MDR GC cells, which indicated that the inhibition of $\mathrm{N}$-glycosylation by Tu determined its specific impacts on MDR cells rather than its role as an ER stress inducer.

\section{Blocking autophagy enhances the inhibitory effects of Tu and Adr on GC cells}

At present, it is widely accepted that ER stress is a potent inducer of autophagy [29-31]. As Tu could significantly activate ER stress in GC cells (as evidenced above), we sought to determine whether Tu-induced ER stress triggered autophagy and the exact role of autophagy in the effects of Tu on GC cells.

We incubated SGC7901 and SGC7901/ADR with Tu $(0.8 \mu \mathrm{g} / \mathrm{ml})$ for $48 \mathrm{~h}$ and then subjected their cell lysates to WB for detection of LC3II/LC3I and P62, which are common markers of autophagy. The results indicated a marked increase in the ratio of LC3II/LC3I and a corresponding decrease in P62 in SGC7901/ADR after Tu treatment but no obvious changes in SGC7901 (Fig. 5a). In addition, the fluorescence of LC3II was also markedly enhanced in SGC7901/ADR after $48 \mathrm{~h}$ treatment of Tu, as shown in Fig. 5b.

We used hydroxychloroquine (HCQ), a lysosome inhibitor, to block autophagic flux, and then identified whether autophagy inhibition impacted the effects of Tu on GC cells. Firstly, we chose $25 \mu \mathrm{M}$ HCQ for further experiments because HCQ effectively inhibited Tu-induced autophagy and exerted little effect on the viability of GC cells at $25 \mu \mathrm{M}$ (Additional file 6: Figure S5). Fig. 5c showed that HCQ significantly decreased the cell viability of $\mathrm{GC}$ cells when combined with the dual therapy of Adr and Tu. Moreover, we discovered that HCQ markedly increased the apoptosis induced by dual therapy of Adr and Tu (Fig. 5d).

Furthermore, WB analysis showed that after the addition of $\mathrm{HCQ}$, the expressions of cleaved caspases and PARP increased compared to those in the CT (Adr and $\mathrm{Tu}$ ) group in GC cells. Besides, we also found a substantial increase in the LC3II/LC3I ratio in GC cells with triple therapy (Adr, Tu and HCQ) (Fig. 5e), which might have resulted from the simultaneous autophagy induction by drugs and autophagic flux blockade by HCQ.

After comprehensive analysis, we found that $\mathrm{Tu}$ could significantly trigger autophagy in MDR cells and that HCQ enhanced the combined effects of Adr and $\mathrm{Tu}$ by inhibiting $\mathrm{Tu}$-induced autophagy. However, in SGC7901, Adr activated autophagy, and HCQ promoted the inhibitory effects of Adr and Tu by blocking Adr-induced autophagy.
In summary, $\mathrm{Tu}$-induced autophagy did not contribute to the effects of Tu on MDR GC cells but rather antagonized its chemosensitizing impacts. Autophagy inhibition could further potentiate the cell death of GC cells induced by $\mathrm{CT}$ with Adr and Tu.

\section{Discussion}

ER stress closely correlates with many hallmarks of cancer, such as angiogenesis, invasion, proliferation and survival, in many types of tumors [25-27, 32]. In addition, a large number of studies have demonstrated the tight relationship between ER stress and chemoresistance in various cancers [33-40]. For example, as one of the three major effectors of UPR, ATF6 $\alpha$ activation plays a vital role in conferring imatinib resistance on leukemia cells, which is regulated by protein disulfide isomerase A5 (PDIA5). In addition, inhibition of the PDIA5/ATF6 $\alpha$ activation loop is able to restore chemosensitivity [37]. Our results revealed that MDR GC cells displayed a high level of basal ER stress, as evidenced by the increases in UPR-associated proteins, implying a correlation between ER stress and chemoresistance in GC. Although ER stress is initially activated as a cytoprotective mechanism, excess or prolonged ER stress can result in apoptosis $[25,26,32]$. Based on this, it seemed that the basal ER stress made MDR cells more vulnerable to Tu-induced cell death compared to the parental cells. In the present study, we found that Tu could preferentially direct MDR cells to death in a time/dose-dependent manner by aggravating ER stress.

Recent studies have demonstrated that $\mathrm{Tu}$ could enhance the antitumor efficacy of both chemotherapy and molecular targeted therapy [21, 41]. For example, Tu sensitized hepatocellular carcinoma to cisplatin-induced apoptosis and reversed drug resistance by regulating the DPAGT1/Akt/ABCG2 pathway [21]. Consistent with these findings, our results demonstrated that cotreatment with $\mathrm{Tu}$ and Adr dramatically decreased the viability of GC cells, especially MDR cells, by triggering ER stress-associated apoptosis. Thus, our findings indicated that $\mathrm{Tu}$ could overcome chemoresistance to some extent by enhancing apoptosis in MDR GC cells.

To define the molecular mechanisms underlying the specific effects of Tu on MDR GC cells, we employed $\mathrm{Tg}$, another widely used ER stress inducer, to imitate the effects of Tu on GC cells. Tu strongly interferes with the N-linked glycosylation of proteins in the ER and thus potently induces ER stress. Tg triggers ER stress by blocking the sarco/endoplasmic reticulum $\mathrm{Ca}^{2+}$ (SER$\mathrm{CA}$ )-adenosine triphosphatase (ATPase) and disrupting $\mathrm{Ca}^{2+}$ homeostasis [42]. Our findings demonstrated that although Tg could also markedly induce ER stress in GC cells, its effects were opposite to those of $\mathrm{Tu}$. In contrast to $\mathrm{Tu}, \mathrm{Tg}$ was more cytotoxic to the parental cells 

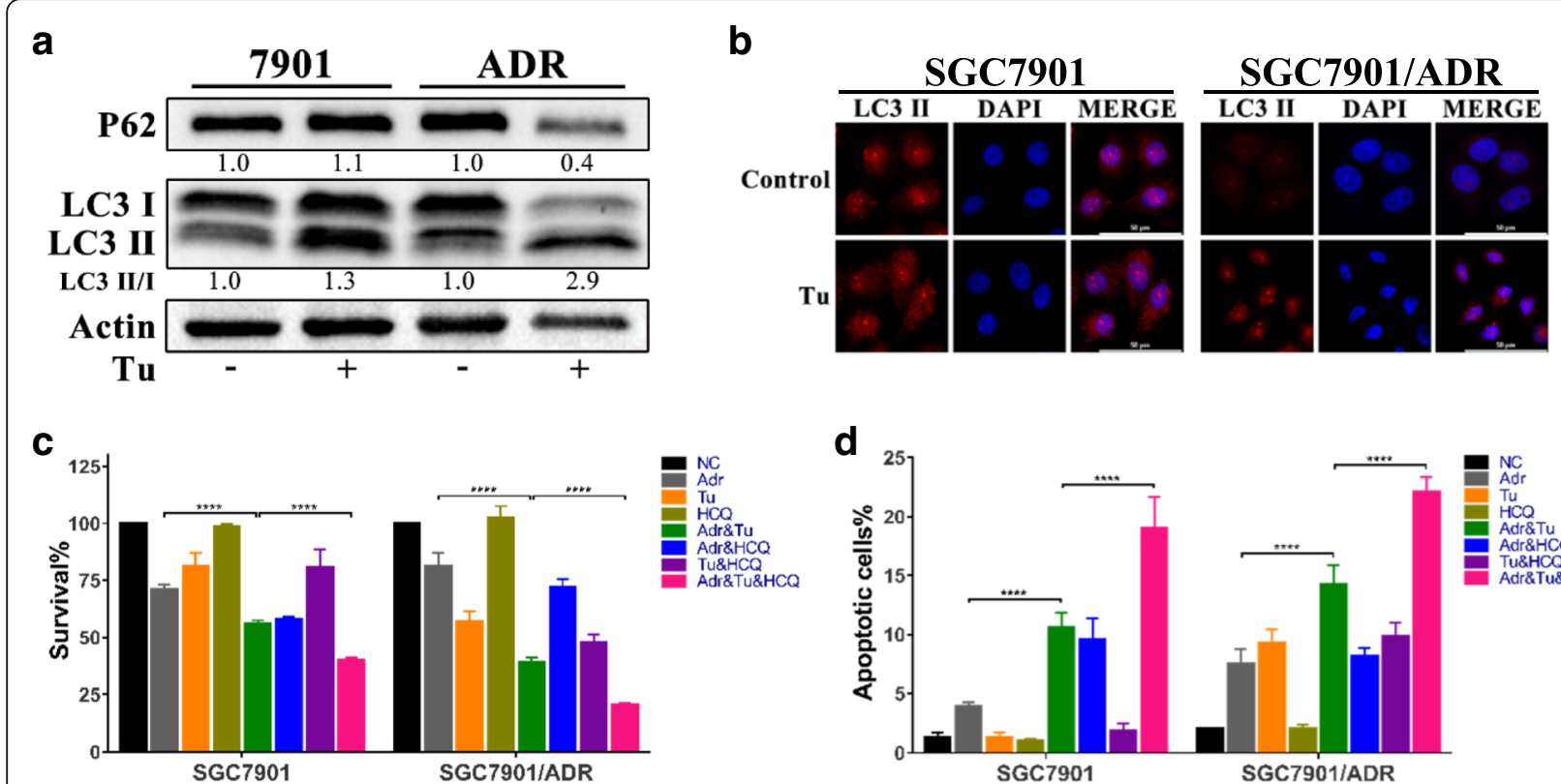

$\mathbf{e}$
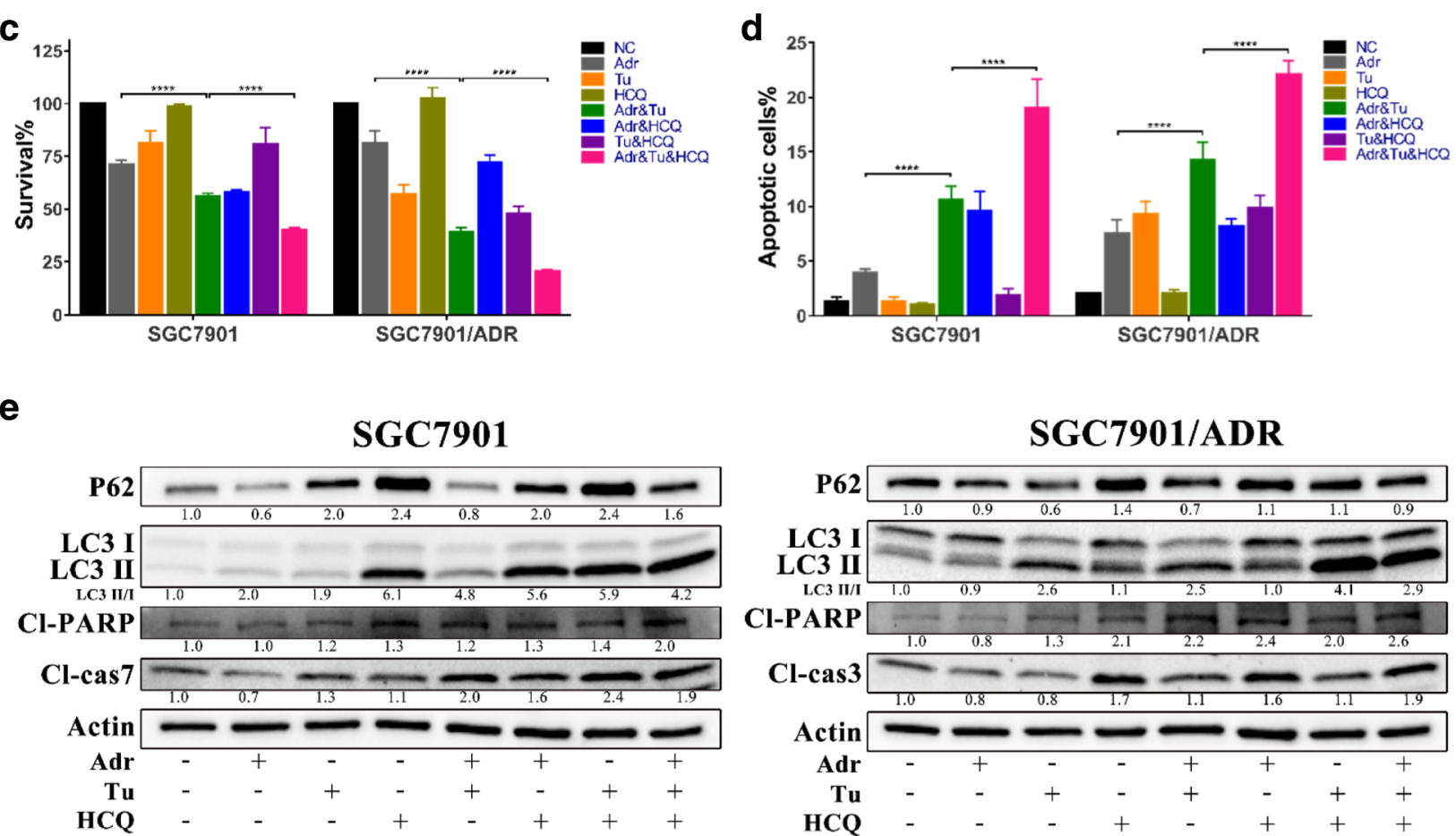

Fig. 5 Tu-induced autophagy antagonizes the chemosensitizing effects of Tu on MDR GC cells. a Expressions of LC3 II and P62 in GC cells after Tu treatment $(0.8 \mu \mathrm{g} / \mathrm{ml})$ for $48 \mathrm{~h}$, as detected by WB. All proteins were normalized to $\beta$-actin. $\mathbf{b}$ Expression of LC3 II in GC cells after Tu treatment $(0.8 \mu \mathrm{g} / \mathrm{ml})$ for $48 \mathrm{~h}$, as detected by IF. (400 x; scale bar, $50 \mu \mathrm{m}$.) c The effects of autophagy blockade on the survival of GC cells assayed by CCK-8. HCQ, hydroxychloroquine; Tu, $0.8 \mu \mathrm{g} / \mathrm{ml}$; HCQ, $25 \mu \mathrm{M} ; \mathrm{Adr}, 0.25 \mu \mathrm{g} / \mathrm{ml}$ for 7901, $8 \mu \mathrm{g} / \mathrm{ml}$ for ADR. Cells were subjected to treatments for $48 \mathrm{~h}$ before the CCK-8 assay. ${ }^{* * *} P<0.0001$. $\mathbf{d}$ The effects of autophagy blockade on the apoptosis of GC cells, as determined by flow cytometry. The treatments were the same as those in $5 c$. ${ }^{* * *} P<0.0001$. e Expression levels of proteins involved in autophagy and apoptosis signaling in GC cells after treatments for $48 \mathrm{~h}$. The treatments were the same as those in $5 \mathrm{c}$. All proteins were normalized to $\beta$-actin

compared to MDR cells and specifically sensitized the parental cells to chemotherapy-induced cell death. Considering that $\mathrm{Tu}$ and $\mathrm{Tg}$ are both canonical ER stress inducers, their entirely different mechanisms of action may result in their contrasting effects on GC cells. Most likely because $\mathrm{Tg}$ cannot inhibit glycosylation, it exerted little effect on the MDR-associated glycoproteins, which subsequently led to the reduced effects of $\mathrm{Tg}$ on MDR cells. Moreover, we also employed BFA to further support these conclusions. Glycosylation occurs sequentially in the ER and Golgi apparatus [43, 44]. BFA can block protein export from the ER to the Golgi apparatus by inhibiting the formation of vesicles, resulting in incomplete glycosylation [45-47]. Our results indicated that BFA could mimic the effects of Tu on MDR cells to some extent. In addition, aberrant glycosylation of proteins activates ER stress and significantly contributes to the development of chemoresistance $[4,8,11,14,48-$ 51]. Thus, we believe that dysregulated glycosylation leads to basal ER stress in MDR GC cells and that Tu further exacerbates ER stress by inhibiting glycosylation, which may account for the specific effects of $\mathrm{Tu}$ on MDR GC cells.

Moreover, recent studies have demonstrated that ER stress can effectively trigger autophagy [29-31, 33, 35, 52]. The three branches of the UPR (PERK, IRE1, ATF6) 
all have marked significance in the induction of autophagy [30, 31, 52-54]. Autophagy (macroautophagy) is an evolutionarily conserved cellular catabolic process involving the formation of double-membrane vesicles named autophagosomes that deliver cellular proteins and organelles to lysosomes, wherein the cargos are degraded and recycled $[55,56]$. Mounting evidence has demonstrated that autophagy has both cytoprotective and cytotoxic functions, which are context-dependent [30, 31, $57,58]$. Notably, it was reported that Tu-induced ER stress could activate autophagy in cancer cells through the IRE1/ JNK signaling pathway $[59,60]$, and inhibiting autophagy by genetic or pharmacological means significantly enhanced the cell death induced by Tu. In contrast, blocking autophagy via bafilomycin A1 or 3-MA markedly increased the survival of mouse embryonic fibroblasts under ER stress [29]. In our study, we also discovered the upregulation of autophagy in MDR GC cells after Tu treatment. To identify the exact role of autophagy in Tu-induced cell death, we subjected GC cells to the common autophagy inhibitor $\mathrm{HCQ}$, which impedes the fusion of autophagosomes with lysosomes by deacidifying lysosomes [61]. We found that autophagy blockade could enhance the inhibitory effects of Adr and Tu on GC cells, though Adr, instead of Tu, induced autophagy in the parental cells. In summary, our results indicated that autophagy played a cytoprotective role against the specific effects of Tu on MDR GC cells.

However, as Tu displayed higher toxicity in normal tissues, we did not perform in vivo studies to further corroborate the combined effects in mouse models. Next, we will collaborate with pharmacologists to develop tumor-targeted drug delivery systems for delivering $\mathrm{Tu}$ and other drugs to further validate these results.

\section{Conclusions}

In summary, we identified for the first time that $\mathrm{Tu}$ could preferentially commit MDR GC cells to apoptosis by inhibiting glycosylation and subsequently exacerbating ER stress (Fig. 6), thus overcoming chemoresistance to some extent. We also revealed that blocking autophagy could markedly enhance the cytotoxicity of $\mathrm{Tu}$ and Adr for GC cells. Our study reconfirms the importance

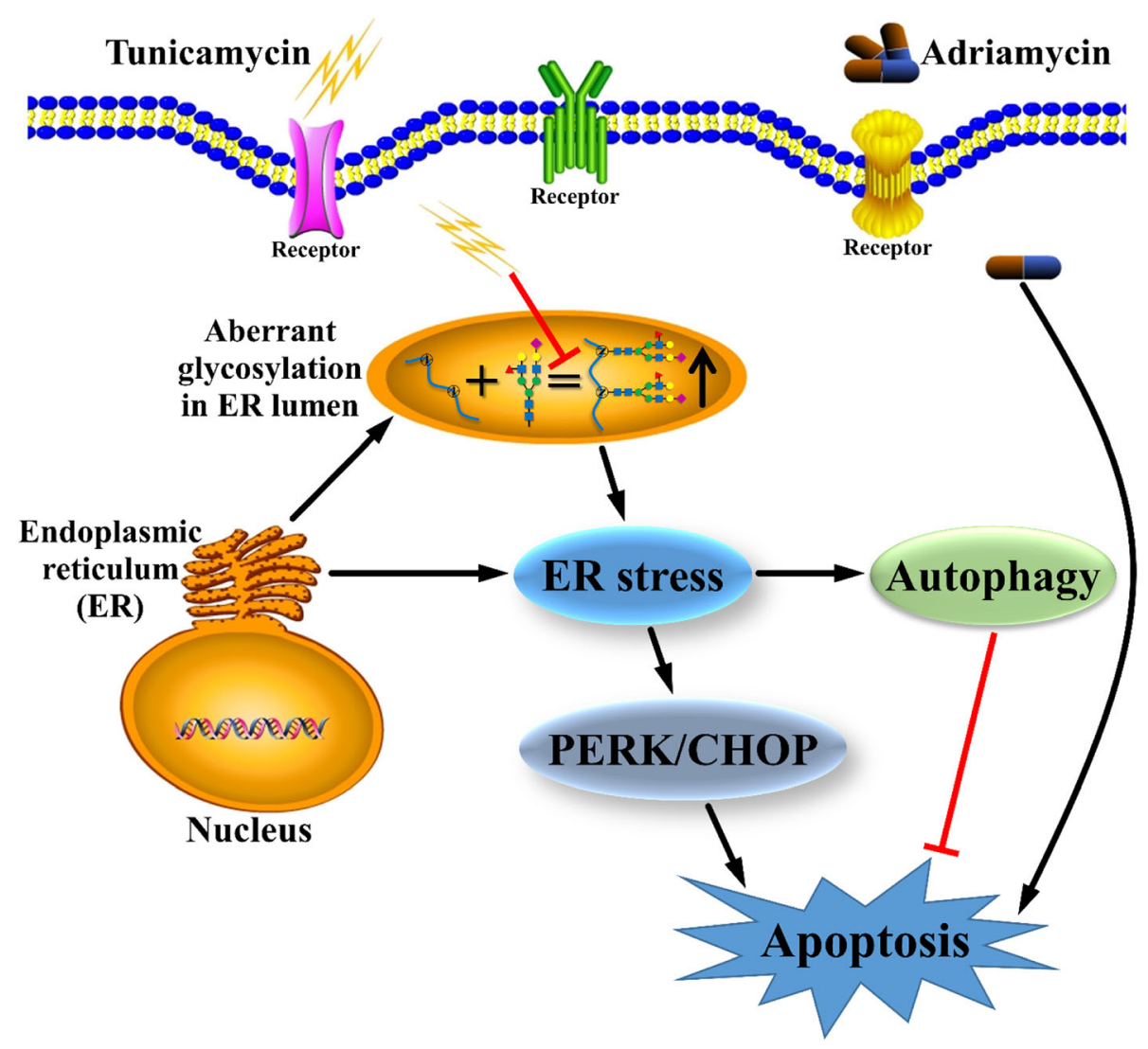

Fig. 6 The schematic diagram illustrates the hypothetical mechanism of action of Tu in MDR GC cells. As previously reported, aberrant glycosylation contributes to chemoresistance. For example, some types of glycosylation are upregulated in MDR cells [13, 14]. Moreover, dysregulated glycosylation leads to basal ER stress in MDR GC cells. Tu further exacerbates ER stress by inhibiting N-glycosylation, and excess ER stress subsequently activates apoptosis signaling, which decreases the chemoresistance of MDR cells to some extent. However, autophagy triggered by ER stress partially dampens the apoptosis-inducing effects of Tu 
of aberrant glycosylation in the multidrug resistance of GC and provides a new insight into the development of novel therapeutic strategies for overcoming chemoresistance in GC.

\section{Additional files}

\section{Additional file 1: Table S1. Cl values for SGC7901, SGC7901/ADR and} SGC7901NCR. CI was calculated by CompuSyn, which is based on the model created by Chou and Talalay. $\mathrm{Cl}<1, \mathrm{Cl}=1$ and $\mathrm{Cl}>1$ represent synergism, additive effect and antagonism, respectively. (XLSX $10 \mathrm{~kb}$ )

Additional file 2: Figure S1. GO analysis of genes significantly changed in SGC7901/ADR after treatment for $48 \mathrm{~h}$ (dual therapy group versus monotherapy group). (a/b) GO analysis of upregulated and downregulated genes, respectively. Dual therapy group, $\mathrm{Adr}(8 \mu \mathrm{g} / \mathrm{ml})$ and Tu $(0.8 \mu \mathrm{g} / \mathrm{ml})$; monotherapy group, $\mathrm{Adr}(8 \mu \mathrm{g} / \mathrm{ml})$, and the control group. (PPTX $301 \mathrm{~kb})$

Additional file 3: Figure S2. Changes in UPR-related genes in SGC7901 after treatment for $48 \mathrm{~h}$ (dual therapy group versus monotherapy group). Group (A \& T), dual therapy with Adr $(0.25 \mu \mathrm{g} / \mathrm{ml})$ and Tu $(0.8 \mu \mathrm{g} / \mathrm{ml})$; Group (A), monotherapy with $\mathrm{Adr}(0.25 \mu \mathrm{g} / \mathrm{ml})$, and the control group. The colored dots represent over-expressed or under-expressed genes; the black dots represent unchanged genes. $P<0.05$. (PPTX $80 \mathrm{~kb}$ )

Additional file 4: Figure S3. Expression levels of $\mathrm{CHOP}, \mathrm{Cl}$-PARP and $\mathrm{Cl}$ caspase 3 in SGC7901 detected by IF after treatment with monotherapy or dual therapy for $48 \mathrm{~h}$. The concentrations of drugs were the same as those in Additional file 3: Figure S2. (400 x; scale bar, 50 um.) (PPTX $556 \mathrm{~kb})$

Additional file 5: Figure S4. Brefeldin A (BFA) can mimic the effects of Tu on MDR GC cells. a The effects of Tu on glycoproteins-L1CAM and TIMP1. GC cells were treated with Tu $(0.8 \mu \mathrm{g} / \mathrm{ml})$ for $48 \mathrm{~h}$ before harvest. All proteins were normalized to $\beta$-actin. $\mathbf{b}$ Concentration-survival curves of GC cells treated with BFA for 48 h. ns, non-significant; $* * * *<0.0001$ (green/red, VCR/ADR versus 7901, respectively). c The effects of BFA on L1CAM and UPR-related proteins in GC cells after treatment $(0.02 \mathrm{\mu g} / \mathrm{ml})$ for $48 \mathrm{~h}$ as determined by WB. All proteins were normalized to $\beta$-actin. $\mathbf{d}$ The effects of BFA on the chemosensitivity of GC cells. BFA, $0.02 \mu \mathrm{g} / \mathrm{ml}$. Cells were subjected to treatments for $48 \mathrm{~h} .{ }^{* * * *} P<0.0001$. (PPTX $315 \mathrm{~kb}$ )

Additional file 6: Figure S5. HCQ (25 $\mu \mathrm{M})$ effectively blocks Tu-induced autophagy and hardly affects the viability of GC cells. a Concentrationsurvival curves of GC cells treated with HCQ for $48 \mathrm{~h}$. $\mathbf{b}$ The effects of HCQ on autophagy-related proteins in SGC7901/ADR. Cells were treated with Tu $(0.8 \mu \mathrm{g} / \mathrm{ml})$ or Tu and HCQ for $48 \mathrm{~h}$ before harvest. All proteins were normalized to $\beta$-actin. (PPTX $144 \mathrm{~kb}$ )

Additional file 7: Figure S6. Representative FCM graphs of SGC7901 (a) and SGC7901/ADR (b) corresponding to the data in Fig. 5d. The treatments were the same as those in Fig. 5d. (PPTX 368 kb)

\section{Abbreviations}

Adr: adriamycin; BFA: brefeldin A; ER: endoplasmic reticulum; GC: gastric cancer; HCQ: hydroxychloroquine; MDR: multi-drug resistant:

Tg: thapsigargin; Tu: tunicamycin; UPR: unfolded protein response

\section{Acknowledgements}

We would like to express our sincere gratitude to all the people who have provided helpful support.

\section{Funding}

This work was supported by the National Natural Science Foundation of China (No. 81430072, No. 81421003).

\section{Availability of data and materials}

The datasets used and/or analyzed during the current study are available from the corresponding author on reasonable request.

\section{Authors' contributions}

DMF, YZN and JW conceived of and designed the study. JW, SC and HL performed the experiments and wrote the manuscript. ZZ, ZN, JC and ZPY contributed to the data analysis and discussion of the results. All authors revised the manuscript and approved the final version for publication.

Ethics approval and consent to participate

Not applicable.

\section{Consent for publication}

Not applicable.

\section{Competing interests}

The authors declare that they have no competing interests.

\section{Publisher's Note}

Springer Nature remains neutral with regard to jurisdictional claims in published maps and institutional affiliations.

Received: 29 May 2018 Accepted: 18 October 2018

Published online: 09 November 2018

\section{References}

1. Chen W, Zheng R, Baade PD, Zhang S, Zeng H, Bray F, et al. Cancer statistics in China, 2015. CA Cancer J Clin. 2016;66:115-32.

2. Torre LA, Bray F, Siegel RL, Ferlay J, Lortet-Tieulent J, Jemal A. Global cancer statistics, 2012. CA Cancer J Clin. 2015:65:87-108.

3. Camargo MC, Kim WH, Chiaravalli AM, Kim KM, Corvalan AH, Matsuo K, et al. Improved survival of gastric cancer with tumour Epstein-Barr virus positivity: an international pooled analysis. Gut. 2014;63:236-43.

4. Very N, Lefebvre T, El Yazidi-Belkoura I. Drug resistance related to aberrant glycosylation in colorectal cancer. Oncotarget. 2018;9:1380-402.

5. Legler K, Rosprim R, Karius T, Eylmann K, Rossberg M, Wirtz RM, et al. Reduced mannosidase MAN1A1 expression leads to aberrant $\mathrm{N}$ glycosylation and impaired survival in breast cancer. Br J Cancer. 2018:118: 847-56

6. Jones RB, Dorsett KA, Hjelmeland AB, Bellis SL. The ST6Gal-I sialyltransferase protects tumor cells against hypoxia by enhancing HIF-1alpha signaling. J Biol Chem. 2018:293:5659-67.

7. Cui J, Huang W, Wu B, Jin J, Jing L, Shi WP, et al. N-glycosylation by Nacetylglucosaminyltransferase $V$ enhances the interaction of CD147/basigin with integrin beta1 and promotes HCC metastasis. J Pathol. 2018:245:41-52.

8. Chakraborty A, Dorsett KA, Trummell HQ, Yang ES, Oliver PG, Bonner JA, et al. ST6Gal-I sialyltransferase promotes chemoresistance in pancreatic ductal adenocarcinoma by abrogating gemcitabine-mediated DNA damage. J Biol Chem. 2018:293:984-94.

9. Rao TD, Fernandez-Tejada A, Axelrod A, Rosales N, Yan X, Thapi S, et al. Antibodies against specific MUC16 glycosylation sites inhibit ovarian Cancer growth. ACS Chem Biol. 2017;12:2085-96.

10. Agrawal P, Fontanals-Cirera B, Sokolova E, Jacob S, Vaiana CA, Argibay D, et al. A systems biology approach identifies FUT8 as a driver of melanoma metastasis. Cancer Cell. 2017;31:804-19.

11. Yen HY, Liu YC, Chen NY, Tsai CF, Wang YT, Chen YJ, et al. Effect of sialylation on EGFR phosphorylation and resistance to tyrosine kinase inhibition. Proc Natl Acad Sci U S A. 2015:112:6955-60.

12. Pinho SS, Reis CA. Glycosylation in cancer: mechanisms and clinical implications. Nat Rev Cancer. 2015:15:540-55.

13. Li K, Sun Z, Zheng J, Lu Y, Bian Y, Ye M, et al. In-depth research of multidrug resistance related cell surface glycoproteome in gastric cancer. J Proteome. 2013:82:130-40.

14. Wu J, Qin H, Li T, Cheng K, Dong J, Tian M, et al. Characterization of sitespecific glycosylation of secreted proteins associated with multi-drug resistance of gastric cancer. Oncotarget. 2016;7:25315-27.

15. Surani MA. Glycoprotein synthesis and inhibition of glycosylation by tunicamycin in preimplantation mouse embryos: compaction and trophoblast adhesion. Cell. 1979:18:217-27.

16. Yoo J, Mashalidis EH, Kuk ACY, Yamamoto K, Kaeser B, Ichikawa S, et al. GICNAc-1-P-transferase-tunicamycin complex structure reveals basis for inhibition of N-glycosylation. Nat Struct Mol Biol. 2018;25:217-24. 
17. Hakulinen JK, Hering J, Branden G, Chen H, Snijder A, Ek M, et al. MraYantibiotic complex reveals details of tunicamycin mode of action. Nat Chem Biol. 2017;13:265-7.

18. Jung YH, Lim EJ, Heo J, Kwon TK, Kim YH. Tunicamycin sensitizes human prostate cells to TRAIL-induced apoptosis by upregulation of TRAIL receptors and downregulation of CIAP2. Int J Oncol. 2012;40:1941-8.

19. Contessa JN, Bhojani MS, Freeze HH, Rehemtulla A, Lawrence TS. Inhibition of N-linked glycosylation disrupts receptor tyrosine kinase signaling in tumor cells. Cancer Res. 2008;68:3803-9.

20. de-Freitas-Junior JC, Bastos LG, Freire-Neto CA, Rocher BD, Abdelhay ES, Morgado-Diaz JA. N-glycan biosynthesis inhibitors induce in vitro anticancer activity in colorectal cancer cells. J Cell Biochem. 2012;113:2957-66.

21. Hou H, Sun H, Lu P, Ge C, Zhang L, Li H, et al. Tunicamycin potentiates cisplatin anticancer efficacy through the DPAGT1/Akt/ABCG2 pathway in mouse xenograft models of human hepatocellular carcinoma. Mol Cancer Ther. 2013;12:2874-84

22. Wojtowicz K, Januchowski R, Nowicki M, Zabel M. Inhibition of protein glycosylation reverses the MDR phenotype of cancer cell lines. Biomed Pharmacother. 2015;74:49-56.

23. Gan PP, Zhou YY, Zhong MZ, Peng Y, Li L, Li JH. Endoplasmic reticulum stress promotes autophagy and apoptosis and reduces chemotherapy resistance in mutant p53 lung Cancer cells. Cell Physiol Biochem. 2017;44: 133-51.

24. Fu YF, Liu X, Gao M, Zhang YN, Liu J. Endoplasmic reticulum stress induces autophagy and apoptosis while inhibiting proliferation and drug resistance in multiple myeloma through the PI3K/Akt/mTOR signaling pathway. Oncotarget. 2017:8:61093-106.

25. Ma Y, Hendershot LM. The role of the unfolded protein response in tumour development: friend or foe? Nat Rev Cancer. 2004;4:966-77.

26. Hetz C, Papa FR. The unfolded protein response and cell fate control. Mol Cell. 2018;69:169-81.

27. Urra H, Dufey E, Avril T, Chevet E, Hetz C. Endoplasmic reticulum stress and the hallmarks of Cancer. Trends Cancer. 2016;2:252-62.

28. Carlberg M, Dricu A, Blegen H, Kass GE, Orrenius S, Larsson O. Short exposures to tunicamycin induce apoptosis in SV40-transformed but not in normal human fibroblasts. Carcinogenesis. 1996;17:2589-96.

29. Qin L, Wang Z, Tao L, Wang Y. ER stress negatively regulates AKT/TSC/mTOR pathway to enhance autophagy. Autophagy. 2010;6:239-47.

30. Huang Z, Zhou L, Chen Z, Nice EC, Huang C. Stress management by autophagy: implications for chemoresistance. Int J Cancer. 2016;139:23-32.

31. Hoyer-Hansen $M$, Jaattela M. Connecting endoplasmic reticulum stress to autophagy by unfolded protein response and calcium. Cell Death Differ. 2007; 14:1576-82

32. Hetz C. The unfolded protein response: controlling cell fate decisions under ER stress and beyond. Nat Rev Mol Cell Biol. 2012;13:89-102.

33. Yan MM, Ni JD, Song D, Ding M, Huang J. Interplay between unfolded protein response and autophagy promotes tumor drug resistance. Oncol Lett. 2015;10:1959-69.

34. Rodvold JJ, Chiu KT, Hiramatsu N, Nussbacher JK, Galimberti V, Mahadevan $N R$, et al. Intercellular transmission of the unfolded protein response promotes survival and drug resistance in cancer cells. Sci Signal. 2017;10: 482.

35. Ma XH, Piao SF, Dey S, McAfee Q, Karakousis G, Villanueva J, et al. Targeting ER stress-induced autophagy overcomes BRAF inhibitor resistance in melanoma. J Clin Invest. 2014;124:1406-17.

36. Lee AS. GRP78 induction in cancer: therapeutic and prognostic implications. Cancer Res. 2007;67:3496-9.

37. Higa A, Taouji S, Lhomond S, Jensen D, Fernandez-Zapico ME, Simpson JC, et al. Endoplasmic reticulum stress-activated transcription factor ATF6alpha requires the disulfide isomerase PDIA5 to modulate chemoresistance. Mol Cell Biol. 2014;34:1839-49.

38. Gifford JB, Huang W, Zeleniak AE, Hindoyan A, Wu H, Donahue TR, et al. Expression of GRP78, master regulator of the unfolded protein response, increases Chemoresistance in pancreatic ductal adenocarcinoma. Mol Cancer Ther. 2016;15:1043-52.

39. Pyrko P, Schonthal AH, Hofman FM, Chen TC, Lee AS. The unfolded protein response regulator GRP78/BiP as a novel target for increasing chemosensitivity in malignant gliomas. Cancer Res. 2007;67:9809-16.

40. Avril T, Vauleon $E$, Chevet $E$. Endoplasmic reticulum stress signaling and chemotherapy resistance in solid cancers. Oncogene. 2017:6:e373.
41. Han X, Zhang X, Li H, Huang S, Zhang S, Wang F, et al. Tunicamycin enhances the antitumor activity of trastuzumab on breast cancer in vitro and in vivo. Oncotarget. 2015;6:38912-25.

42. Sehgal $P$, Szalai $P$, Olesen C, Praetorius HA, Nissen P, Christensen SB, et al. Inhibition of the sarco/endoplasmic reticulum (ER) ca (2+)-ATPase by thapsigargin analogs induces cell death via ER ca (2+) depletion and the unfolded protein response. J Biol Chem. 2017;292:19656-73.

43. Kornfeld R, Kornfeld S. Assembly of asparagine-linked oligosaccharides. Annu Rev Biochem. 1985:54:631-64.

44. Varki A. Biological roles of glycans. Glycobiology. 2017;27:3-49.

45. Sampath D, Varki A, Freeze HH. The spectrum of incomplete N-linked oligosaccharides synthesized by endothelial cells in the presence of brefeldin a. J Biol Chem. 1992;267:4440-55.

46. Peyroche A, Antonny B, Robineau S, Acker J, Cherfils J, Jackson CL. Brefeldin a acts to stabilize an abortive ARF-GDP-Sec7 domain protein complex: involvement of specific residues of the Sec7 domain. Mol Cell. 1999;3:27585.

47. Klausner RD, Donaldson JG, Lippincott-Schwartz J, Brefeldin A. Insights into the control of membrane traffic and organelle structure. J Cell Biol. 1992; 116:1071-80.

48. Britain CM, Holdbrooks AT, Anderson JC, Willey CD, Bellis SL. Sialylation of EGFR by the ST6Gal-I sialyltransferase promotes EGFR activation and resistance to gefitinib-mediated cell death. J Ovarian Res. 2018;11:12.

49. Ferreira JA, Peixoto A, Neves M, Gaiteiro C, Reis CA, Assaraf YG, et al. Mechanisms of cisplatin resistance and targeting of cancer stem cells: adding glycosylation to the equation. Drug Resist Updat. 2016;24:34-54.

50. Feng X, Zhao L, Gao S, Song X, Dong W, Zhao Y, et al. Increased fucosylation has a pivotal role in multidrug resistance of breast cancer cells through miR-224-3p targeting FUT4. Gene. 2016;578:232-41.

51. da Fonseca LM, da Silva VA, Freire-de-Lima L, Previato JO, MendoncaPreviato L, Capella MA. Glycosylation in Cancer: interplay between multidrug resistance and epithelial-to-mesenchymal transition? Front Oncol. 2016;6:158.

52. Kouroku Y, Fujita E, Tanida I, Ueno T, Isoai A, Kumagai $H$, et al. ER stress (PERK/elF2alpha phosphorylation) mediates the polyglutamine-induced LC3 conversion, an essential step for autophagy formation. Cell Death Differ. 2007:14:230-9

53. Urano F, Wang X, Bertolotti A, Zhang Y, Chung P, Harding HP, et al. Coupling of stress in the ER to activation of JNK protein kinases by transmembrane protein kinase IRE1. Science. 2000;287:664-6.

54. Wang J, Kang R, Huang H, Xi X, Wang B, Wang J, et al. Hepatitis C virus core protein activates autophagy through EIF2AK3 and ATF6 UPR pathwaymediated MAP1LC3B and ATG12 expression. Autophagy. 2014;10:766-84.

55. Mizushima N. Autophagy: process and function. Genes Dev. 2007:21:286173

56. Mizushima N, Yoshimori T, Ohsumi Y. The role of Atg proteins in autophagosome formation. Annu Rev Cell Dev Biol. 2011;27:107-32.

57. Singh SS, Vats S, Chia AY, Tan TZ, Deng S, Ong MS, et al. Dual role of autophagy in hallmarks of cancer. Oncogene. 2018;37:1142-58.

58. Levy JMM, Towers CG, Thorburn A. Targeting autophagy in cancer. Nat Rev Cancer. 2017;17:528-42.

59. Ogata M, Hino S, Saito A, Morikawa K, Kondo S, Kanemoto S, et al. Autophagy is activated for cell survival after endoplasmic reticulum stress. Mol Cell Biol. 2006;26:9220-31.

60. Cheng $X$, Liu H, Jiang CC, Fang L, Chen C, Zhang XD, et al. Connecting endoplasmic reticulum stress to autophagy through IRE1/JNK/beclin-1 in breast cancer cells. Int J Mol Med. 2014:34:772-81.

61. Yang YP, Hu LF, Zheng HF, Mao CJ, Hu WD, Xiong KP, et al. Application and interpretation of current autophagy inhibitors and activators. Acta Pharmacol Sin. 2013;34:625-35. 